litis lethargica in the winter months of December to February inclusive. Poliomyelitis, unlike encephalitis lethargica, attacks chiefly children. Experimentally, the unidentified virus of each disease appears to be a filtrable organism, that of poliomyelitis being readily transmissible to monkeys; that of encephalitis lethargica being transmissible with difficulty and only from acute cases of the disease.

The detailed pathological and bacteriological evidence of the separate identity of these two diseases cannot be given here, but it is set out lucidly in Dr. MacNalty's contribution to the report under review.

The separate identity of influenza is sufficiently indicated by its proverbial infectiousness, whereas multiple cases of either encephalitis lethargica or poliomyelitis are a rarity. Even if it be assumed that the apparent partial non-infectiousness of these two diseases is due to the incarceration of the hypothetical influenzal virus in the deep parts of the central nervous system, it would still need explanation that the virus when introduced in these cases did not cause, e.g. in other members of the same family, ordinary attacks of influenza. There is no systematic parallelism in the prevalence of the three diseases; and as Dr. Parsons remarks, "the epidemic behaviour of influenza and encephalitis lethargica do not seem to represent a mutuality of any constant nature." The rarity of respiratory complications in cases of encephalitis lethargica is in itself a strong argument against community of origin.

The present reports by Dr. A. C. Parsons, Dr. A. S. MacNalty, and Dr. J. R. Perdrau, with a prefatory statement by Sir George Newman, bring our knowledge of this disease up-to-date. The value of the report is enhanced by an elaborate bibliography of 1243 items, which will be most useful to students of this obscure subject. The extent of incidence of the disease may be gathered from the statement that in $1919,54 \mathrm{I}$ cases, and in I920, 890 cases, were recognised and notified, and it is not without significance that cases of poliomyelitis became much fewer in the same. period. This may be explained on the supposition that a common virus at different times strikes at different parts of the nervous system; but the totality of evidence, epidemiological, clinical, and pathological, points in another direction.

We began this necessarily sketchy review with a statement that the group of diseases mentioned above do not yet come within the range of practical preventive medicine. When the agitation in one of our chief daily journals in favour of the much-needed Ministry of Health was at its height, the failure of the Local Government Board to control the pandemic of influenza was a big item in the indictment against it. This report, like the recent official report on influenza, should give pause to those who anticipate that uncontrollable diseases will be made controllable by changing the name of a government department. It has to be confessed-and from a scientific point of view it is most important to face the fact-that "respiratory infections" like influenza and (presumably) poliomyelitis and encephalitis lethargica are almost entirely uncontrollable, and will remain so until some new method of securing immunity is discovered, or until a standard of hygienic precautions is reached in respect of coughing, and even of speaking, which is not likely to be attained universally in this century. Even were it attainable, would life then be tolerable?

Meanwhile, every channel of investigation needs to be pursued ; and a word of praise may be given in this connexion to the wisdom of making encephalitis lethargica notifiable in 1918 as soon as its separate existence was fairly well established. By this means it has become practicable to investigate each notified case and to demonstrate the general absence of personal infection from recognised cases. By implication we are led to infer that slight unrecognisable cases of the disease exist which cause its spread; but this fact further emphasises the uncontrollable character of the disease in present circumstances.

Encephalitis lethargica has been described above as a "new disease." This merely means that it is a newly recognised disease. Crookshank and others have searched older literature and found descriptions which tally with this disease, occurring commonly in association with epidemics of influenza; and there can be little doubt that the apparent strict modernity of encephalitis lethargica is indeed apparent and not real.

\section{The Telescope.}

The Telescope. By Dr. Louis Bell. Pp. ix +287 . (London: McGraw-Hill Publishing Co., Ltd., I922.) I $5^{s}$. net.

TNENTION is not the prerogative of the learned. The telescope, we are told, was the creation of the two little children of an observant father, a spectaclemaker of Holland. But, however casual the origin, its development was the result of laborious and progressive experiment and study, an excellent account of which is given by Dr. Louis Bell in the introductory chapter of the work before us.

There are partisans who will dissent from some of the author's historical statements, and many who will object to the presentation of Newton as a "blunderer," a "bungler," and a man who promptly jumped to a conclusion. As a boy, Newton tested the wind by jumping with and against it, and Sir David Brewster remarks : "This mode of jumping to a conclusion, or reaching it per saltum, was not the one which our

NO. 2767 , VOL. I IO] 
philosopher afterwards used." Dr. Bell has the same authority for the statement that, when investigating the relationship of dispersion to mean refraction, Newton mixed sugar of lead with the water. Traced to its source, however, this so-called fact appears to be merely a suggestion of Mr. Michell, a friend of Dr. Priestley, offered as an explanation of an otherwise inexplicable experimental result and based on Newton's use of saccharum saturni in other experiments.

Flint glass good enough for quantitative observation could scarcely have existed in $\mathbf{1 6 6 6}$, for about a hundred and forty years elapsed before Guinand resolved the optical glass problem. It was more the absence of suitable material that "delayed the production of the achromatic telescope by some three-quarters of a century" than any action of Newton. Indeed, Sir Isaac Newton should be honoured for his prescience in recognising that in the circumstances the practice of astronomy could best be advanced by the development of the reflector.

"The Telescope" has been "written for the many observers who use telescopes for study or pleasure and desire more information about their construction and properties," the information hitherto published on the subject being "for the most part scattered through papers in three or four languages and quite inaccessible to the ordinary reader." Within the limits of a single volume the author has collected a great deal of essential information that the general reader will find both useful and interesting.

Following the historical introduction there are chapters on the modern telescope, optical glass and its working, properties of objectives and mirrors, mountings, eyepieces, hand telescopes and binoculars, accessories, the testing and care of telescopes, setting up and housing, seeing and magnification, and finally, a brief appendix on work for the telescope.

The book is not free from mistakes. In the description, for example, of the Galilean glass, the field is stated to be approximately measured by the angle subtended at the centre of the objective by the pupil. The description given in "The Telescope" by Herschel, although theoretically incomplete, might have been copied with advantage, as it explains how the field is determined by the diameter of the objective and the possible displacement of the eye. In chapter 7 the so-called Dove prism system is described as the rudiment of the prism binocular or shortened telescope. Such a system, unlike the earlier Porro combination, cannot be placed in the convergent beam and it cannot serve to shorten the telescope.

Those to whom style and composition are of importance will regret the inelegance of such expressions as "credulous twaddle," "pricked up its ears," and "blast of hot air." Their use detracts from the pleasure of perusal of a welcome addition to the literature of the telescope. JAMES WEIR FRENCH.

\section{An Elementary Work on Coal-Mining.}

An Elementary Text-Book of Coal-Mining. By Robert

Peel. Revised and enlarged by Prof. Daniel Burns. Twentieth edition. Pp. viii +420. (London and Glasgow : Blackie and Son, Ltd., x922.) 6s. net.

7 HIS little book is, as its title expresses, a book dealing with the most elementary principles of coal-mining. It has obviously answered its purpose extremely well, and has suited the needs of those to whom it is particularly addressed, as is only too evident from the fact that it has reached its twentieth edition since its original publication twenty-nine years ago. It need scarcely be said, therefore, that the general arrangement and style of the work are beyond criticism, otherwise it would not have survived the rigorous test of experience through which it has passed. Any review of the work must therefore be based upon the nature of the revision to which it has been subjected.

It may fairly be said that the labour of revising such a work falls under three main heads, namely, first to eliminate all possible blunders; secondly, to bring the work thoroughly up-to-date, and thirdly, to see that there is no ambiguity likely to puzzle the student. Unfortunately, it cannot be said that the revision stands the test under any of these three heads, and a couple of illustrative examples of shortcomings may be quoted under each. There are, for example, blunders in spelling, such as "Plainmeller" for "Plenmeller" and "Maudline" for "Maudlin." Under the second heading we have such statements as that the deepest borehole in the world is that at Schladebach, which attained the depth of 956 fathoms. This was true once, but the deepest borehole in the world to-day is that at Czuchow, Rybnik; Upper Silesia, which has attained a depth of $735^{\circ}$ feet. Again, the statement that of centrifugal fans those most generally adopted are the Guibal, Waddle, and Schiele was true once, but is not true to-day. The only reference given to the Kind-Chaudron method of sinking in this country is its first application at Marsden, the far more important, instructive, and recent sinking at Dover not being mentioned. Under the third head we get such a statement as that when it is inconvenient to state work in foot-pounds as the unit of work a higher unit is adopted termed horse-power. The confusion between work and power, to which most students are prone, is one that should never be allowed to creep into a text-book, where the difference between the two standards should be very clearly explained. Again, in dealing with the thickness of tubbing, two 